\title{
Preclinical evaluation of the Hsp90 inhibitor SNX-5422 in ibrutinib resistant CLL
}

\author{
Timothy L. Chen ${ }^{1}$, Bonnie Harrington 1,2, Jean Truxall', Ronni Wasmuth ${ }^{1}$, Alexander Prouty ${ }^{1}$, Shelby Sloan ${ }^{1}$, \\ Amy M. Lehman ${ }^{3}$, Deepa Sampath', Eric Orlemans ${ }^{4}$, Robert A. Baiocchi ${ }^{1}$, Lapo Alinari ${ }^{1}$, John C. Byrd ${ }^{1,5}$, \\ Jennifer A. Woyach ${ }^{1+}$ and Erin Hertlein ${ }^{1 *+}$ (1)
}

\begin{abstract}
B-cell receptor (BCR) antagonists such as the BTK inhibitor ibrutinib have proven to effectively target chronic lymphocytic leukemia (CLL) tumor cells, leading to impressive response rates in these patients. However patients do still relapse on ibrutinib, and the progressive disease is often quite aggressive requiring immediate treatment. Several strategies are being pursued to treat patients who relapse on ibrutinib therapy. As the most common form of relapse is the development of a mutant form of BTK which limits ibrutinib binding, agents which lead to degradation of the BTK protein are a promising strategy. Our study explores the efficacy of the Hsp90 inhibitor, SNX-5422, in CLL. The SNX Hsp90 inhibitor was effective in primary CLL cells, as well as B-cell lines expressing either BTK wild type or C481 mutant BTK, which has been identified as the primary resistance mechanism to ibrutinib in CLL patients. Furthermore the combination of SNX-5422 and ibrutinib provided a remarkable in vivo survival benefit in the EH-TCL1 mouse model of CLL compared to the vehicle or single agent groups (51 day median survival in the vehicle and ibrutinib groups versus 100 day median survival in the combination). We report here preclinical data suggesting that the Hsp90 inhibitor SNX-5422, which has been pursued in clinical trials in both solid tumor and hematological malignancies, is a potential therapy for ibrutinib resistant CLL.
\end{abstract}

Keywords: Chronic lymphocytic leukemia, Hsp90, BTK

To the editor,

In the front-line setting, agents targeting B-cell receptor (BCR) signaling have shown extremely promising results, and are an option for initial therapy in patients with Chronic Lymphocytic Leukemia (CLL) [1]. For patients with relapsed CLL the median progression free survival in CLL patients treated with ibrutinib was 44.1 months, with a cumulative overall response rate of $91 \%$. Nevertheless, ibrutinib was discontinued in $37 \%$ of CLL patients

\footnotetext{
*Correspondence: erin.hertlein@osumc.edu

${ }^{\dagger}$ Jennifer A. Woyach and Erin Hertlein have contributed equally to this work

${ }^{1}$ Division of Hematology, Department of Internal Medicine, The Ohio State University, 462 OSUCCC, 410 W 12th Avenue, Columbus, OH 43210, USA

Full list of author information is available at the end of the article
}

due to progressive disease [2], and patients who relapse on ibrutinib progress quickly and have poor overall survival [3]. Patients who progress on BTK inhibitors which rely on the $\mathrm{C} 481$ binding site develop frequent mutations in BTK (C481S) which circumvents BTK inhibition in $\sim 85 \%$ of cases [4]. Therefore combinatorial approaches to target mutant BTK could eliminate the mutant clone allowing the patient to continue on ibrutinib.

One promising clinical strategy in patients with resistant CLL is Hsp90 inhibition to target the BTK protein. Esanex Pharmaceuticals developed a novel Hsp90 inhibitor, SNX-5422 (the prodrug of SNX-2112) which has been safely tested in multiple phase I studies in solid tumors and hematological malignancies [5-7]. In treatment-naïve primary CLL cells we see reduced proliferation with as low as 0.1uM SNX-2112 (Fig. 1a) original author(s) and the source, provide a link to the Creative Commons licence, and indicate if changes were made. The images or other third party material in this article are included in the article's Creative Commons licence, unless indicated otherwise in a credit line to the material. If material is not included in the article's Creative Commons licence and your intended use is not permitted by statutory regulation or exceeds the permitted use, you will need to obtain permission directly from the copyright holder. To view a copy of this licence, visit http://creativecommons.org/licenses/by/4.0/. The Creative Commons Public Domain Dedication waiver (http://creativeco mmons.org/publicdomain/zero/1.0/) applies to the data made available in this article, unless otherwise stated in a credit line to the data. 


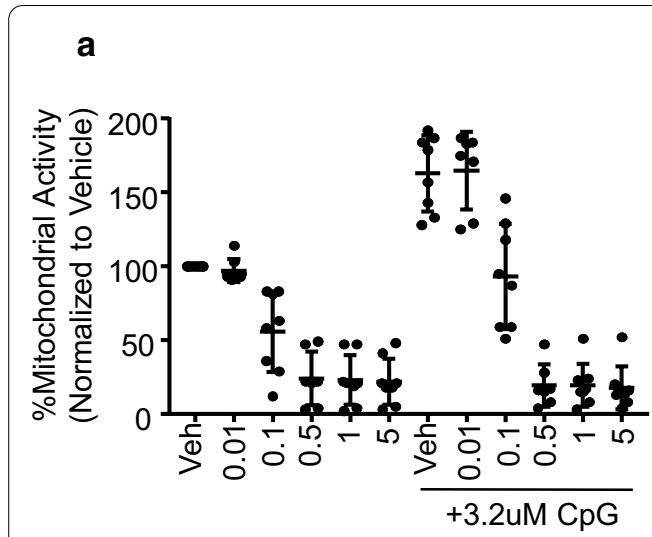

C
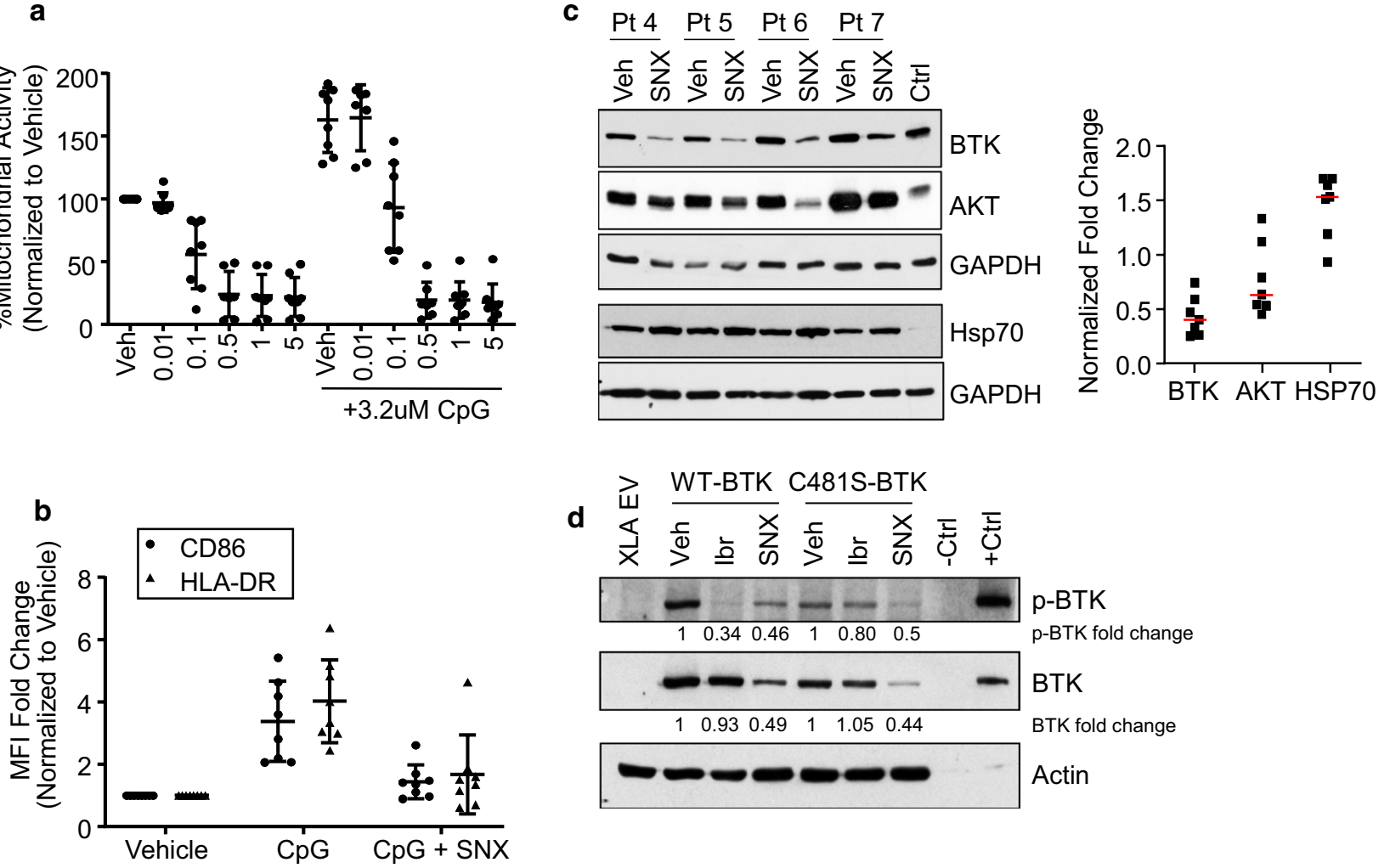

Fig. 1 a CLL B-cells ( $N=8$ ) were plated in 96-well plates at 400,000 cells per well. Cells were treated with either vehicle, 0.5uM SNX-2112, or 3.2uM $\mathrm{CpG}+0.5 \mathrm{uM}$ SNX-2112 for $48 \mathrm{~h}$ followed by addition of MTS reagents and samples were read at 490 $\mathrm{nm}$. b CLL B-cells $(N=8)$ were treated with either vehicle, 3.2uM CpG, or 3.2uM CpG + 0.5uM SNX-2112. CD19+ and live cells were stained and analyzed by flow cytometry for HLA-DR and CD86 surface expression. c CLL B-cells isolated from the peripheral blood of patient samples $(N=7)$ were treated with vehicle or $0.5 \mathrm{uM}$ SNX-2112 for $16 \mathrm{~h}$. Whole cell lysates were isolated and immunoblots performed to determine total levels of BTK, AKT and Hsp70 protein, as well as the loading control GAPDH (left). Immunoblots for all patient samples were quantified and the fold change in protein is shown (right; normalized to GAPDH then displayed as fold change relative to the vehicle treatment). The red line indicated the average fold change for all 7 samples. The control lysate (Ctrl) is isolated from Mec1 B-cells. $\mathbf{d}$ XLA cell lines (BTK null) were transfected to express either wild type or C481S mutant BTK. Cell lines were then treated for $16 \mathrm{~h}$ with vehicle, $1 \mathrm{uM}$ ibrutinib (for $1 \mathrm{~h}$ followed by washout), or 100nM SNX-2112. Whole cell lysates were collected and immunoblot analysis performed for phospho-BTK and total BTK, as well as the loading control Actin. Immunoblots were quantified and the fold change in protein is shown below the graph (normalized to Actin then displayed as fold change relative to the vehicle). The control lysates are parental 293T cells (Ctrl -) and 293T cells over-expressing BTK protein (Ctrl +)

including CpG stimulated primary CLL cells which mimics the natural stimulation of the tumor microenvironment (Fig. 1b). Furthermore we found that downstream mediators of BCR signaling, BTK and AKT, are consistently down-regulated in all patient samples examined (Fig. 1c). Furthermore while ibrutinib is able to reduce BTK autophosphorylation at Y223 in cells expressing wild type BTK protein, cells expressing C481S mutated BTK $[8,9]$ are resistant (Fig. 1d). However we see a reduction in both phospho and total BTK with 0.1uM SNX-2112 in both WT and C481S BTK cell lines.

Next, we tested the efficacy of SNX-5422 in combination with ibrutinib using a E $\mu$-TCL1 CLL ibrutinib resistant model previously reported by our group [10, 11]. Mice dosed with vehicle or ibrutinib had similar overall survival, however the combination of SNX-5422 and ibrutinib provided remarkable survival benefit (Fig. 2a; 51 day median survival in the vehicle and ibrutinib groups versus 100 day median survival in the combination; $p<0.01$ ). Mice treated with SNX-5422 had smaller spleens when compared to vehicle and ibrutinib treated mice (Fig. 2b, SNX-5422+ibrutinib vs. vehicle or ibrutinib: $p<0.001$ ), with a trend towards decreased peripheral blood tumor development (green line, Fig. 2c). Finally, histopathological analysis of leukemic infiltration into surrounding tissues revealed that mice treated with combination therapy had reduced severity of neoplastic infiltrates in liver, spleen, and lung (Fig. 2d). We performed an additional in vivo study using the E $\mu$-BRD2 model which develops an aggressive lymphoma with splenomegaly, 




Fig. 2 a Kaplan-Meier estimates of overall survival in mice engrafted with ibrutinib resistant TCL1 splenocytes and treated with vehicle, ibrutinib (30 $\mathrm{mg} / \mathrm{kg}$ daily in drinking water), SNX-5422 (50 mg/kg 3 days/week) or the combination. The log-rank p-value between the combination SNX-5422 + ibrutinib vs either vehicle or ibrutinib was calculated (combo vs vehicle, $p=0.007$; combo vs ibrutinib, $p=0.002$ ). b Mice spleens were weighed at early removal criteria and compared between treatment groups (combo vs vehicle, $p<0.001$; combo vs ibrutinib, $p<0.001$; vehicle vs ibrutinib, $p=$ 0.035). c Weekly peripheral blood disease burden evaluated by \%CD19+CD5+ of CD45+ cells of mice described in Figure $3 \mathrm{~A}$ and that are alive at each time point. $\mathbf{d}$ Histopathology performed on spleen, lymph node, liver, lung and bone marrow reveals reduced leukemic infiltration in the liver, lungs, and marrow of SNX-5422 and SNX-5422 + ibrutinib treated groups

abdominal lymphadenopathy and leukemic infiltrations of liver and lung [12]. While there was not a significant survival advantage (Additional file 1A) there was reduced splenic tumor burden in the SNX-5422 treated mice (Additional file 1B) and a complete absence of neoplasia in the SNX-5422 treated animals at time of death (Additional file $1 \mathrm{C}$ ).

We did note reduced survival in the single agent SNX5422 treated mice despite the reduced tumor burden, therefore we performed detailed histopathology in both in vivo models. Surprisingly, there was marked ulceration of the non-glandular stomach (Additional file 2; indicated by black arrows) accompanied by immune cell infiltration (indicated by red arrows), and hyperplasia of the surrounding squamous gastric mucosa (indicated by green arrows) which was less severe in mice treated with the combination. As these ulcers only occurred in the non-glandular stomach (an anatomic counterpart lacking in humans), this toxicity is unlikely to occur in human patients receiving SNX-5422, which was safe and tolerable with a recommended dose of $100 \mathrm{mg} / \mathrm{m}^{2}$ QOD 3 weeks on and 1 week off in phase I solid tumor trials [5]. Interestingly, in both models these symptoms appear to be less severe in mice treated with the combination, suggesting that ibrutinib is ameliorating some of the toxicities related to SNX-5422.

Altogether, our data suggest that Hsp90 inhibition in combination with ibrutinib may be an option for initial treatment in CLL to prevent the outgrowth of a resistant clone in patients who display high risk features that 
are less likely to have a prolonged response to ibrutinib. The safety and pharmacology of SNX-5422 has been explored in clinical trials in solid tumors (NCT01611623) and hematological malignancies (NCT01635712). However, studies to determine the efficacy in CLL in patients receiving ibrutinib therapy (NCT02973399, NCT02914327) have not been completed due to low enrollment and have not been published. This is likely attributed to the overall success of ibrutinib and other BTK inhibitors, as well as newer generation BTK inhibitors that do not rely on the C481S binding site currently in development. Nevertheless our work shows that alternative strategies that target BTK for degradation are a promising option in BTK inhibitor resistant CLL.

\section{Supplementary Information}

The online version contains supplementary material available at https://doi. org/10.1186/s13045-021-01039-9.

Additional file 1. E $\mu-B R D 2$ in vivo model. A Kaplan-Meier estimates of overall survival in mice engrafted with ibrutinib resistant BRD2 splenocytes and treated with vehicle, ibrutinib (30 mg/kg daily in drinking water), SNX-5422 (50 mg/kg 3 days/week) or the combination. B Mice spleens were weighed at early removal criteria and compared between treatment groups. C Histopathology performed on spleen, lymph node, liver, lung and bone marrow reveals reduced leukemic infiltration in the liver, lungs, and marrow of SNX-5422 and SNX-5422 + ibrutinib treated groups. (C, lymph node cortex; $M$, lymph node medulla; $W$, spleen white pulp; $R$, spleen red pulp)

Additional file 2. SNX-5422 related toxicity. Histopathology of the murine non-glandular stomach reveals gastric ulcers in SNX-5422 treated groups

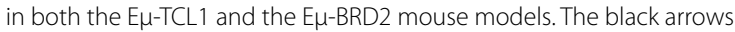
indicate the damage to the gastric mucosal layer in the SNX-5422 and combo treated mice, red arrows indicate immune cell infiltration, and green arrows indicate mucosal hyperplasia.

\section{Abbreviations}

CLL: Chronic lymphocytic leukemia; BCR: B-cell receptor; BTK: Bruton's tyrosine kinase; XLA: X-linked agammaglobulinemia.

\section{Acknowledgements}

Not applicable

\section{Authors' contributions}

TLC designed and conducted experiments, generated data and figures, analyzed data, interpreted results, and wrote the manuscript; $\mathrm{BH}$ conducted experiments and generated figures; AP, JT, RW and SS performed animal experiments; AL conducted all statistical analysis; EO contributed critical reagents, LA RAB, JCB and JAW planned the project, interpreted results, reviewed the manuscript; and obtained funding and $\mathrm{EH}$ planned the project, supervised the study, analyzed data, interpreted results, reviewed the manuscript; and obtained funding. All authors read and approved the final version of the manuscript. All authors read and approved the final manuscript.

\section{Funding}

This work was supported by the National Cancer Institute (R35 CA197734-01, P01 CA81534, K12 CA133250, and OSUCCC Core Facilities P30 CA016058), Sullivan Foundation, The Leukemia and Lymphoma Society (special scholar Grant to $\mathrm{EH}$ ) and The D. Warren Brown Foundation.

\section{Availability of data and materials}

All data collected during this study are included in this published article or the supplementary information.

\section{Ethics approval and consent to participate}

The authors are grateful to the patients who generously provided blood for these studies. Blood from CLL patients was obtained from the Ohio State University Leukemia Tissue Bank after obtaining informed consent approved by the cancer institution review board (IRB). All mouse protocols were reviewed and approved by The Ohio State University Institutional Animal Care and Use Committee (IACUC).

\section{Consent for publication \\ Not applicable.}

\section{Competing interests}

At the time these studies were completed, E.O held the position of chief scientific officer for Esanex who provided SNX-2112 and SNX-5422 for this work.

\section{Author details}

${ }^{1}$ Division of Hematology, Department of Internal Medicine, The Ohio State University, 462 OSUCCC, 410 W 12th Avenue, Columbus, OH 43210, USA ${ }^{2}$ Department of Pathobiology and Diagnostic Investigation, College of Veterinary Medicine, Michigan State University, East Lansing, MI, USA. ${ }^{3}$ Center for Biostatistics, Department of Biomedical Informatics, The Ohio State University, Columbus, OH, USA. ${ }^{4}$ Esanex Inc., Indianapolis, IN, USA. ${ }^{5}$ Division of Pharmaceutics, College of Pharmacy, The Ohio State University, Columbus, $\mathrm{OH}, \mathrm{USA}$.

Received: 7 October 2020 Accepted: 28 January 2021

Published online: 24 February 2021

\section{References}

1. Jain N, O'Brien S. Targeted therapies for CLL: practical issues with the changing treatment paradigm. Blood Rev. 2015;30:233-44.

2. Munir T, Brown JR, O'Brien S, Barrientos JC, Barr PM, Reddy NM, et al. Final analysis from RESONATE: up to six years of follow-up on ibrutinib in patients with previously treated chronic lymphocytic leukemia or small lymphocytic lymphoma. Am J Hematol. 2019;94(12):1353-63.

3. Maddocks KJ, Ruppert AS, Lozanski G, Heerema NA, Zhao W, Abruzzo $L$, et al. Etiology of ibrutinib therapy discontinuation and outcomes in patients with chronic lymphocytic leukemia. JAMA Oncol. 2015;1(1):80-7.

4. Woyach JA, Furman RR, Liu TM, Ozer HG, Zapatka M, Ruppert AS, et al. Resistance mechanisms for the Bruton's tyrosine kinase inhibitor ibrutinib. N Engl J Med. 2014;370(24):2286-94.

5. Infante JR, Weiss GJ, Jones S, Tibes R, Bauer TM, Bendell JC, et al. Phase I dose-escalation studies of SNX-5422, an orally bioavailable heat shock protein 90 inhibitor, in patients with refractory solid tumours. Eur J Cancer. 2014;50(17):2897-904.

6. Rajan A, Kelly RJ, Trepel JB, Kim YS, Alarcon SV, Kummar S, et al. A phase I study of PF-04929113 (SNX-5422), an orally bioavailable heat shock protein 90 inhibitor, in patients with refractory solid tumor malignancies and lymphomas. Clin Cancer Res. 2011;17(21):6831-9.

7. Reddy N, Voorhees PM, Houk BE, Brega N, Hinson JM Jr, Jillela A. Phase I trial of the HSP90 inhibitor PF-04929113 (SNX5422) in adult patients with recurrent, refractory hematologic malignancies. Clin Lymphoma Myeloma Leuk. 2013;13(4):385-91.

8. Reiff SD, Mantel R, Smith LL, Greene JT, Muhowski EM, Fabian CA, et al. The BTK inhibitor ARQ 531 targets ibrutinib-resistant CLL and richter transformation. Cancer Discov. 2018;8(10):1300-15.

9. Reiff SD, Muhowski EM, Guinn D, Lehman A, Fabian CA, Cheney C, et al. Noncovalent inhibition of C481S Bruton tyrosine kinase by GDC-0853: a new treatment strategy for ibrutinib-resistant CLL. Blood. 2018;132(10):1039-49.

10. Hing ZA, Mantel R, Beckwith KA, Guinn D, Williams E, Smith LL, et al. Selinexor is effective in acquired resistance to ibrutinib and synergizes with ibrutinib in chronic lymphocytic leukemia. Blood. 2015;125(20):3128-32.

11. Woyach JA, Bojnik E, Ruppert AS, Stefanovski MR, GoettI VM, Smucker KA, et al. Bruton's tyrosine kinase (BTK) function is important to the development and expansion of chronic lymphocytic leukemia (CLL). Blood. 2014;123(8):1207-13. 
12. Greenwald RJ, Tumang JR, Sinha A, Currier N, Cardiff RD, Rothstein $T L$, et al. E $\mu$-BRD2 transgenic mice develop B-cell lymphoma and leukemia. Blood. 2004;103(4):1475-84.

\section{Publisher's Note}

Springer Nature remains neutral with regard to jurisdictional claims in published maps and institutional affiliations.
Ready to submit your research? Choose BMC and benefit from:

- fast, convenient online submission

- thorough peer review by experienced researchers in your field

- rapid publication on acceptance

- support for research data, including large and complex data types

- gold Open Access which fosters wider collaboration and increased citations

- maximum visibility for your research: over $100 \mathrm{M}$ website views per year

At BMC, research is always in progress.

Learn more biomedcentral.com/submissions 